\title{
Genç Futbolcularda Sürat, Güç ve El Kavrama Kuvvet Değerleri Arasındaki İlişkinin İncelenmesi
}

\author{
Halit EGESOY ${ }^{*}$ (D) Eylem ÇELİK ${ }^{\circledR D}$, Ayşegül YAPICI ÖKSÜZOĞLU \\ ${ }^{1}$ Pamukkale Üniversitesi Spor Bilimleri Fakültesi
}

Orijinal Makale

Gönderi Tarihi: 01.11.2021
Kabul Tarihi: 29.12.2021
DOI:10.30769/usbd.1017370

Online Yayın Tarihi: 31.12.2021

\section{Öz}

Bu çalışmanın amacı genç futbolcularda sürat, güç ve el kavrama kuvvet değerleri arasındaki ilişkinin incelenmesidir. Araştırmaya bir profesyonel futbol takımının U-15 ve U-16 kategorilerinde futbol oynayan yaşları 15,54 $\pm 0,51$ yıl, boy uzunlukları 1,75 $\pm 0,07$

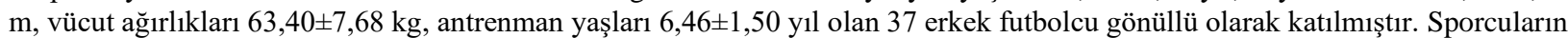
önce vücut ağırlıkları ve boy uzunlukları ölçülmüş daha sonra sırasıyla 30m sürat, durarak uzun atlama, dikey sıçrama ve el kavrama kuvvet testleri uygulanmıştır. Tüm parametreler ortalama ve standart sapma değerleri ile ifade edilmiştir. Veriler normal dağılım göstermiş olup tüm parametreler arasındaki ilişki pearson korelasyon analizi ile test edilmiştir. Genç futbolcuların ortalama sprint değerleri $4.78 \pm 0.18 \mathrm{~s}$, dikey sıçrama değerleri $35.70 \pm 3.34 \mathrm{~cm}$, durarak uzun atlama değerleri $2.03 \pm 0.11 \mathrm{~m}$, dominant el (sağ) kavrama kuvveti değeri $37.26 \pm 4.53 \mathrm{~kg}$ ve sol el kavrama kuvveti değeri $35.97 \pm 3.82 \mathrm{~kg}$ olarak bulunmuştur. Çalışma bulguları incelendiğinde, deneklerin nondominant el kavrama kuvveti ile $30 \mathrm{~m}$ sürat ve durarak uzun atlama değerleri arasında $\mathrm{p}<0.05$ düzeyinde bir ilişki tespit edilmiştir. Ayrıca deneklerin dikey sıçrama değeri ile $10 \mathrm{~m}-30 \mathrm{~m}$ sürat ve durarak uzun atlama değerleri arasında $\mathrm{p}<0.01$ düzeyinde anlamlı ilişkiler olduğu belirlenmiştir. Diğer değişkenler arasında ise herhangi anlamlı bir ilişki bulunmamıştır ( $>0.05)$. Sonuç olarak, sporcuların el kavrama kuvveti değerleriyle sürat ve dikey sıçrama değerleri arasında anlamlı bir ilişkisi bulunmamıştır. Sporcuların dominant el kavrama kuvveti değerinin dominant olmayan el değerine daha yüksek olduğu gözlenmiştir. Çalışma sonuçlarına göre sporcuların el kavrama kuvvetlerinin, sürat ve güç değerlerine olumlu katkı sağlamadığı söylenebilir.

Anahtar Kelimeler: Sporcu, sürat, güç, el kavrama kuvveti

\section{Investigating the Relationship between Speed, Power and Hand Grip Strength in Young Soccer Players}

\begin{abstract}
The aim of this study is to investigate the relationship between speed, power and hand grip strength values of young soccer players.

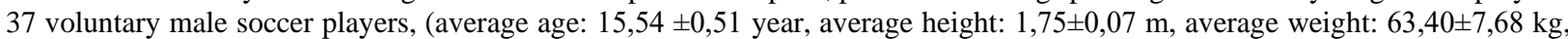
average sport background 6,46 $\pm 1,50$ year), who exercise at a soccer club (U-15, U-16 teams) in Denizli participated in this study. First, the body weights and heights of the athletes were measured, then $30 \mathrm{~m}$ speed, standing long jump, vertical jump and hand grip strength tests were applied respectively. All parameters were expressed as mean and standard deviation values. The data showed normal distribution and the relationship between all parameters was tested by pearson correlation analysis. The average values of players were $4.78 \pm 0.18 \mathrm{~s}$ in sprint, $35.70 \pm 3.34 \mathrm{~cm}$ in vertical jump, $2.03 \pm 0.11 \mathrm{~m}$ in the long jump. The grip strength values of the players were $37.26 \pm 4.53 \mathrm{~kg}$ in dominant hand and $35.97 \pm 3.82 \mathrm{~kg}$.in left hand. When the study findings were examined, a relationship was found at $\mathrm{p}<0.05$ level between the subjects' non-dominant hand grip strength and $30 \mathrm{~m}$ sprint and standing long jump values. In addition, it was determined that there was a significant relationship at $\mathrm{p}<0.01$ level between the vertical jump values of the subjects and the $10 \mathrm{~m}-30 \mathrm{~m}$ sprint and standing long jump values. No significant relationship was found between the other variables. As a result, there was no significant relationship among hand grip strength, speed and vertical jump values. It was observed that the dominant hand grip strength of the athletes was higher than the non-dominant hand value. According to the results of the study, it can be said that athletes do not contribute to hand grip strengths, speed and power values. Keywords: Athlete, speed, power, hand grip strength
\end{abstract}

\footnotetext{
*Sorumlu Yazar: Halit EGESOY, Dr. Öğr. Üyesi, E posta: hegesoy1 @ hotmail.com
} 


\section{GíRIŞ}

Futbolda sporcuların optimal performans gelişimleri için gelişmiş teknik, taktik, mental ve kondisyonel becerilere ihtiyaçları olduğu bilinmektedir. Futbol, değişen şiddetlerde uzun süreli ani yön değiştirmeli koşuları içeren aerobik tabanlı anaerobik bir spor dalıdır. Futbol oyunu sırasında, farklı sürelerde çok sayıda sprint, negatif ve pozitif ivmelenme, sıçrama, kuvvet ve çeviklik gerektiren hareketler sıklıkla meydana gelmektedir (Shephard, 1999; Reilly ve Williams, 2003; Stolen, Chamari, Castagna ve Wisloff, 2005). Bu nedenle dayanıkl1lık, kuvvet, güç, sürat ve çeviklik gibi motorik özellikler, futbolcuların önemli performans bileşenleridir. Oyunun ve oyuncuların fizyolojik gereksinimlerinin bilinmesi, bireysel antrenman programının hazırlanması, enerji ihtiyaçlarını belirleme ve sakatlanma risklerini azaltma gibi konularda antrenörlere yardımcı olmaktadır (Köklü, Özkan, Alemdaroğlu ve Ersöz, 2009; O’Donoghue, Boyd, Lawlor ve Bleakley, 2001). Futbolcuların antrenman ve maç sırasındaki performanslarını etkileyen birçok faktör bulunmaktadır. Bu faktörler arasında oyunun yapısı ve kuralları, oyuncuların taktik ve teknik açıdan beceri düzeyleri, fiziksel faktörler, oyun tarzları, oynadıkları mevkiler, iletişim yeteneği ve çevresel koşullar yer almaktadır (Reilly, 1996).

Futbolda oyun sirasında sporcunun, toplu ya da topsuz rakiplerinden daha süratli olmas1, yüksekten gelen toplarda daha yükseğe sıçraması, ikili mücadelelerde kassal olarak daha güçlü kalması onun başarısına katkıda bulunacaktır. Bu yüzden çocuk futbolcularda ileriye dönük başarı için, beceri ve yeteneğin yanında fiziksel ve motorsal özelliklerin geliştirilmesi de oldukça önemlidir. Futbolda başarıya giden yolun anahtarı öncelikle futbol için uygun olan oyuncuların bulunması ve bu oyuncuların performansının artırılmasına bağlıdır. Genç sporcular geleceğin sporcularını temsil etmektedir ve genç sporcuların performanslarındaki değişimlerin incelenmesi oldukça önem taşımaktadır. Literatürde sıklıkla yetişkin sporcularla ilişkili çalışmalar bulunmaktadır. Buradan hareketle yetişkin sporcularda sürat, güç ve kuvvet arasındaki ilişkinin incelendiği çalışmalar bulunmasına rağmen (Vescovi ve McGuigan, 2008; Young, Mcdowell ve Scarlett, 2001; Young ve Farrow, 2006), genç sporcularda bu parametreler arasındaki ilişkiyi inceleyen çalışmaların sınırlı sayıda olması yapılan bu çalışmayı önemli hale getirmiştir. Bu çalışmanın amacı, genç futbolcularda sürat, güç ve el kavrama kuvvet değerleri arasındaki ilişkinin incelenmesidir.

\section{YÖNTEM}

\section{Araştırma Grubu}

Araştırmaya bir profesyonel futbol takımının U-15 ve U-16 kategorilerinde futbol oynayan

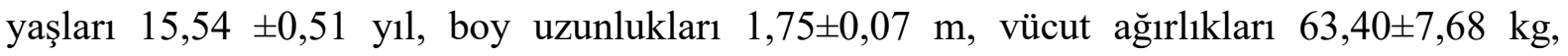

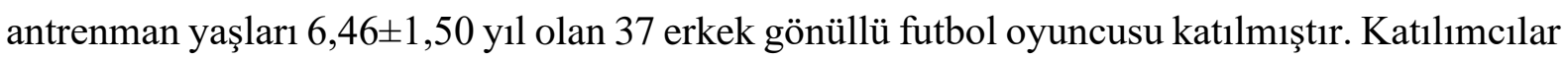
18 yaşından küçük oldukları için veli izin belgesi ve ilgili spor kulübü izinleri alınmıştır.

Katılımcılar, çalışmanın amacı ve uygulanacak değerlendirme yöntemleri hakkında sözlü ve yazılı olarak bilgilendirilmiş ve tüm sporculardan 'Bilgilendirilmiş Gönüllü Olur Formu' alınmıştır. Katılımcıların fiziksel özellikleri olarak yaş, boy uzunluğu, vücut ağırlığı ve antrenman yaşı değerleri, yapılandırılmış bir değerlendirme formuna kaydedilmiştir. 


\section{Verilerin Toplanması}

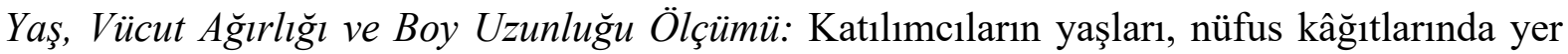
alan doğum yılları esas alınarak belirlenmiştir. Fiziksel ölçümlerden vücut ağırlığı, Tanita (Japonya) marka ve 100 gr hassaslığındaki vücut yağ analizöründe, boy ölçümü ise Holtaine (İngiltere) marka stadiometre ile $0,1 \mathrm{~cm}$ duyarlılıkta yapılmıştır. Futbolcular çıplak ayaklı olarak ve sadece spor kıyafeti giydirilerek tartılmışlardır. Boy ölçümlerinde, denekler ayakta dik pozisyonda dururken, skalanın üzerinde kayan kaliper futbolcunun başın en üst (apex) noktasına dokunacak şekilde ayarlanmıştır ve uzunluk $1 \mathrm{~mm}$ hassasiyetle okunup kaydedilmiştir (Gordon, Churchill, Clauser, ve Bradtmiller, 1989).

Sprint Testi: Deneklere teste başlamadan önce $10 \mathrm{dk}$ 'lı standart bir 1sınma protokolü uygulanmıştır. Teste denek, başlangıç fotoselinin bir metre gerisinde bulunan başlangıç çizgisinden istediği zaman başlamıştır. Ölçümler, 30 m'lik koşu mesafesinin 10, 20 ve 30'uncu metrelerine yerleştirilen fotoseller ile yapılmıştır. 3'er dakikalık dinlenme aralıklarıyla iki kez ölçüm alınmış ve iyi olan derece saniye/salise cinsinden kaydedilmiştir (Özkara, 2002).

Durarak Uzun Atlama Testi (DUA): Denekten, iki ayak parmak uçları önceden belirlenmiş bir çizginin hemen arkasına gelecek şekilde durması istenmiştir. Daha sonra çizginin arkasından adım almadan olduğu yerde çömelmesi ve hemen akabinde ileriye doğru hızla sıçrama yapması söylenmiştir. Deneğin düştüğü yerde ayak topuğunun temas ettiği son nokta ile sıçrama çizgisi arasındaki mesafe kaydedilmiştir. Her bir deneğe iki deneme hakkı verilmiş ve yaptığı en iyi sıçrama değeri kaydedilmiştir (Karavelioğlu, 2008).

Dikey Sıçrama Testi: My Jump akıllı telefon uygulaması sporcunun sıçrama esnasında havada kaldığı süreyi notasyon yöntemini kullanarak belirledikten sonra dikey sıçrama yüksekliğini hesaplayan bir uygulamadır. Bu uygulama ile katılımcıların sıçrama esnasında ayak parmak uçlarının kuvvet platformundan ayrıldığı ve tekrar konuşlandığ 1 an manuel olarak belirlenip sıçramada uçuş süresi hesaplanmıştır (Balsalobre-Fernándeza vd., 2015). Bu uygulama ile iki ölçüm yapılmış ve sporcunun en iyi derecesi cm cinsinden kaydedilmiştir. Denemeler arasında 2 dakika dinlenme verilmiştir.

El Kavrama Kuvveti Testi: Sporcuların el kavrama kuvvetlerini ölçmek için Takei (T.K.K. 5101 model-Japan) marka el dinamometresi kullanılmıştır. Denekten kolunu $45^{\circ}$ yan tarafa açması ve maksimum kuvvetini kullanarak el dinamometresini sıkması istenmiştir. Bu ölçüm her iki el için ayrı ayrı yapılmıştır. Test iki defa tekrar edilmiş ve en iyi derece kg cinsinden kaydedilmiştir (Günay vd., 2006).

\section{Verilerin Analizi}

Tüm parametreler ortalama ve standart sapma değerleri ile ifade edilmiştir. Verilerinin normal dağılım gösterip göstermediğini test etmek amaciyla ShapiroWilks Normallik Analizi uygulanmıştır. Verilerin normal dağılım gösterdiği belirlenmiş ve tüm parametreler arasındaki ilişki Pearson Korelasyon Analizi ile test edilmiştir. Anlamlılık düzeyi $p<0.05$ olarak alınmıştır. 


\section{BULGULAR}

Yapılan ölçümler neticesinde, sporcuların ölçüm değerlerinin aritmetik ortalaması ve standart sapması Tablo 1'de verilmiştir.

Tablo 1. Katılımcıların ölçüm değerlerinin aritmetik ortalaması ve standart sapması

\begin{tabular}{lcccc}
\hline Değişkenler & Ortalama & Ss. & Min. & Maks. \\
\hline Yaş (yıl) & 15,54 & 0,51 & 15 & 16 \\
Antrenman Yaşı (yıl) & 6,46 & 1,50 & 4 & 9 \\
Boy Uzunluğu (cm) & 175,22 & 0,07 & 1,63 & 1,88 \\
Vücut Ağırlığı (kg) & 63,40 & 7,68 & 45,9 & 80,2 \\
10 m sprint (s) & 2,09 & 0,09 & 1,94 & 2,26 \\
20 m sprint (s) & 3,40 & 0,14 & 3,21 & 3,72 \\
30 m sprint (s) & 4,78 & 0,18 & 4,33 & 5,06 \\
Durarak Uzun Atlama (m) & 2,03 & 0,11 & 1,8 & 2,36 \\
Dikey Sıçrama (cm) & 35,70 & 3,34 & 30,2 & 46,6 \\
Dominant El Kavrama Kuvveti (kg) & 37,26 & 4,53 & 32,10 & 58,50 \\
Nondominant El Kavrama Kuvveti (kg) & 35,97 & 3,82 & 30,30 & 50,10 \\
\hline
\end{tabular}

Tablo 2. Katılımcıların sprint, sıçrama ve el kavrama kuvveti değerleri arasındaki ilişki tablosu

\begin{tabular}{|c|c|c|c|c|c|c|c|}
\hline & & $\begin{array}{c}\text { 20m } \\
\text { Sprint } \\
(\mathrm{s})\end{array}$ & $\begin{array}{l}\text { 30m } \\
\text { Sprint } \\
\text { (s) }\end{array}$ & $\begin{array}{c}\text { Durarak } \\
\text { Uzun } \\
\text { Atlama (m) }\end{array}$ & $\begin{array}{c}\text { Dikey } \\
\text { Sıçrama } \\
\text { (cm) }\end{array}$ & $\begin{array}{c}\text { Dominnat El } \\
\text { Kavrama } \\
\text { Kuvveti (kg) }\end{array}$ & $\begin{array}{c}\text { Nondominant } \\
\text { El Kavrama } \\
\text { Kuvveti (kg) }\end{array}$ \\
\hline \multirow[t]{2}{*}{10 m Sprint (s) } & $\mathbf{p}$ & 0,67 & 0,56 & $-0,50$ & $-0,46$ & 0,04 & $-0,19$ \\
\hline & $\mathbf{r}$ & $0,00 * *$ & $0,00^{* *}$ & $0,00 * *$ & $0,00 * *$ & 0,80 & 0,26 \\
\hline \multirow[t]{2}{*}{20 m Sprint (s) } & $\mathbf{p}$ & & 0,32 & $-0,30$ & $-0,35$ & 0,12 & $-0,01$ \\
\hline & $\mathbf{r}$ & & 0,05 & 0,08 & $0,03 *$ & 0,48 & 0,98 \\
\hline \multirow[t]{2}{*}{30 m Sprint (s) } & $\mathbf{p}$ & & & $-0,45$ & $-0,52$ & $-0,27$ & $-0,41$ \\
\hline & $\mathbf{r}$ & & & 0,01 & $0,00 * *$ & 0,11 & $0,01 *$ \\
\hline \multirow{2}{*}{$\begin{array}{l}\text { Durarak } \\
\text { Atlama (m) }\end{array}$} & $\mathbf{p}$ & & & & 0,55 & 0,22 & 0,38 \\
\hline & $\mathbf{r}$ & & & & $0,00 * *$ & 0,19 & $0,02 *$ \\
\hline \multirow[t]{2}{*}{ Dikey Sıçrama (cm) } & $\mathbf{p}$ & & & & & 0,15 & 0,28 \\
\hline & $\mathbf{r}$ & & & & & 0,37 & 0,09 \\
\hline Să̆ El Kavrama & $\mathbf{p}$ & & & & & & 0,75 \\
\hline Kuvveti (kg) & $\mathbf{r}$ & & & & & & $0,00 * *$ \\
\hline
\end{tabular}

$* \mathrm{p}<0.005$ ve $* * \mathrm{p}<0.01$

Tablo 2' de katılımcıların sprint, dikey sıçrama ve kuvvet özellikleri arasındaki ilişkiler korelasyon analizi ile incelendiğinde, katılımcıların $30 \mathrm{~m}$ sprint ile dikey sıçrama değerleri arasında $\mathrm{p}<0.05$; DUA ve dikey sıçrama değerleri arasında ve sağ el kavrama kuvveti ile sol el kavrama kuvveti değerleri arasında $\mathrm{p}<0.01$ düzeyinde anlamlı ilişkiler bulunduğu tespit edilmiştir. Diğer değişkenler arasında ise anlamlı bir ilişki bulunamamıştır $(\mathrm{p}>0.05)$. 


\section{TARTIŞMA}

Futbolcuların sürat ve dikey sıçrama performansları, anaerobik performanslarının iyi bir göstergesi olarak kabul edilmektedir (Eniseler, 1995). Sporcuların alt ekstremite gücünü değerlendirmede aktif ve skuat sıçrama testleri sıklıkla kullanılmaktadır (Cardinale vd., 2011). Son dönemlerde sporcuların motorik özellikleri arasındaki ilişkiler araştırmacıların ilgisini çekmiştir. Araştırmacıların, sporcuların fiziksel özelliklerini geliştirmeyi hedefleyen çalışmalara daha fazla önem verdikleri görülmüştür. Yapılan çalışmalarda sporcuların performans gelişimleri ve bunları etkileyen faktörler araştırılmıştır (Taşkın vd., 2015).

$\mathrm{Bu}$ çalışma, genç futbolcularda sürat, güç ve el kavrama kuvvet değerleri arasındaki ilişkinin incelenmesi amacıyla yapılmıştır. Bu çalışmada katılımcıların ortalama yaş değeri 15,54 yıl, boy uzunluğu değeri $175,22 \mathrm{~cm}$ ve vücut ağırlığı değeri de 63,40 kg olarak tespit edilmiştir. Çalışma bulguları incelendiğinde, katılımcıların $30 \mathrm{~m}$ sprint değeri ile dikey sıçrama değerleri arasında $p<0.05$; DUA ve dikey sıçrama değerleri arasında ve sağ el kavrama kuvveti ile sol el kavrama kuvveti değerleri arasında $p<0.01$ düzeyinde anlamlı ilişkiler bulunduğu tespit edilmiştir. Diğer değişkenler arasında ise herhangi anlamlı bir ilişki bulunamamıştır ( $\mathrm{p}>0.05)$.

Literatürde yapılan bazı çalışmalarda, sporcuların el kavrama kuvveti değerleriyle sürat ve dikey sıçrama değerleri arasında anlamlı bir ilişkisi bulunmasına rağmen (Girard ve Millet, 2009; Kramer vd., 2016; Wisloff vd., 2004; Vescovi ve McGuigan, 2008) bazı çalışmalarda ise bu ilişki tespit edilememiştir (Brechue vd., 2010; Cerrah vd., 2011; Kamar vd., 2011; Seiler vd., 1990). Yapılan çalışmada, sporcuların el kavrama kuvveti değerleriyle sürat ve dikey sıçrama değerleri arasında anlamlı bir ilişkisi bulunmamıştır. Ayrıca, sporcuların dominant el kavrama kuvveti değerinin dominant olmayan el değerine daha yüksek olduğu tespit edilmiştir.

Literatürde dominant elin, nondominant ele göre \%10 daha fazla kavrama kuvvetine sahip olduğu belirtilmektedir (Armstrong ve Oldham, 1999). Çocuklarda kas kuvvetinin gelişiminin yaş, vücut yapısı ve cinsel olgunlaşmayla ilgili olduğu bilinmektedir (Seger ve Thorstensson, 2000). Konuyla ilgili yapılan bir çalışmada, dominant elin, nondominant ele göre \%10 daha fazla kavrama kuvvetine sahip olduğu belirlenmiştir (Peterson vd.,1989). Yapılan bir başka çalışmada ise katılımcıların dominant ve nondominant elleri arasında \%0,1-\%0,3 arasında bir fark bulunmuştur (Armstrong vd., 1999). Bu çalışmada bulunan el kavrama kuvveti sonuçlarının, diğer çalışmaların bulgularından daha yüksek çıktığı tespit edilmiştir. Bunun sebebi olarak uygulanan antrenman metodunun, büyüme dönemlerinin, spor yaşının, spor branşının ve antrenman periyodunun farklı olması gösterilebilir. Çalışma sonuçlarına göre sporcuların el kavrama kuvvet değerlerinin, sprint ve güç (sıçrama ve durarak uzun atlama) değerlerine olumlu katkı sağlamadığı söylenebilir. Kramer vd., (2016) tarafindan elit çocuk tenisçiler üzerinde yapılan bir çalışmada ise sporcuların patlayıcı güç değerleri ile 5-10 m sprint performansları arasında anlamlı ilişki olduğu rapor edilmiştir. Girard ve Millet, (2009) ortalama yaşları 13 olan yarışmacı tenisçilerin, sürat (5-10-20m), patlayıcı güç, alt ve üst ekstremite kas kuvvetleri arasındaki ilişkiyi inceledikleri çalışmalarında, patlayıcı güç ile $5 \mathrm{~m}, 10 \mathrm{~m}$ ve $20 \mathrm{~m}$ sürat arasında anlamlı bir ilişki tespit etmişlerdir. Literatür çalışmalarının (Girard ve Millet, 2009; Kramer vd., 2016) sonuçlarına baktığımızda, durarak uzun atlama/patlayıcı güç ile kısa mesafe sürat (5-10-20 m) arasında bulunan ilişki, çalışma sonuçlarımızı destekler niteliktedir. Yıldız vd., (2017) çocuk tenisçilerde yapmış oldukları çalışmada patlayıcı güç, sürat, esneklik, çeviklik ve denge parametrelerinin birbirleri ile ilişkili olup, bu özelliklerde sağlanan performans artışının fonksiyonel hareket performansını da arttırdığını ifade etmişlerdir. Taşkın 
vd., (2015) futbolcular ile yapmış olduğu benzer bir çalışmada durarak uzun atlama ile $30 \mathrm{~m}$ sürat ve dikey sıçrama ile $30 \mathrm{~m}$ sürat arasında anlamlı bir ilişki rapor etmişlerdir. Kamar vd., (2003) futbolcular ile yapmış oldukları başka bir araştırmada, sporcuların $35 \mathrm{~m}$ sprint ve durarak uzun atlama değerleri arasında anlamlı bir ilişki olduğunu rapor etmişlerdir. Yapılan bir başka çalışmada, 2. ve 3. liglerde oynayan futbolcuların sıçrama, akselerasyon ve yön değiştirme becerileri incelenmiştir. Çalışma bulgularında, sporcuların skuat sıçrama ile 5-10-15 m sprint değerleri arasında orta düzey, aktif sıçrama ile 5-10-15 m sprint değerleri arasında ise güçlü bir ilişki olduğu belirlenmiştir (Los Arcos vd., 2014). Zileli ve Söyler (2021) tarafından yapılan bir çalışmada, sporcuların 10-30m sprint değerleriyle aktif ve skuat sıçrama değerleri arasında istatistiksel olarak anlamlı bir ilişki olduğu rapor edilmiştir. Wisloff vd., (2004) tarafından yapılan bir başka çalışmada, Norveç milli futbol takımı sporcularının dikey sıçrama değerleriyle 10-30 m sprint değerleri arasında anlamlı bir ilişki olduğu belirlenmiştir. Ayrıca yapılan benzer bir başka çalışmada, 2 lig'de oynayan futbolcuların aktif ve pasif sıçrama değerleri ile 5-10m sprint değerleri arasında anlamlı bir ilişki olmadığı fakat 30m sprint değerleri arasında ise anlamlı bir ilişki olduğu rapor edilmiştir (Yelken vd., 2018). Bunun yanında, yapılan benzer bazı çalışmalarda, Seiler vd., (1990) ve Brechue vd., (2010) katılımcıların dikey sıçrama ve sprint parametreleri arasında zayıf bir ilişki olduğunu tespit etmişlerdir. Ayrıca, Yitik (2020) tarafından yapılan bir başka çalışmada, sporcuların aktif ve skuat sıçrama değerleriyle 10-30 m sprint değerleri arasında anlamlı olmayan bir ilişki olduğu rapor edilmiştir. Cerrah vd., (2011) futbolcular üzerinde yapmış oldukları çalışmalarında, deneklerin 1030 m sprint değerleriyle bacak kuvveti ve dikey sıçrama değerleri arasında anlamlı bir ilişki olmadığını tespit etmişlerdir.

\section{SONUÇ VE ÖNERILER}

Çalışma bulguları incelendiğinde, katılımcıların $30 \mathrm{~m}$ sprint ile dikey sıçrama değerleri arasında $\mathrm{p}<0.05$; DUA ve dikey sıçrama değerleri arasında ve sağ el kavrama kuvveti ile sol el kavrama kuvveti değerleri arasında $\mathrm{p}<0.01$ düzeyinde anlamlı ilişkiler bulunduğu tespit edilmiştir. Durarak uzun atlamada, sıçramadan sonra vücut ağırlığının öne doğru hareket etmesi ve kütleye ivme kazandırarak yer değiştirmesi sağlanmaktadır. Kısa mesafe sürate baktığımızda ise sporcu, patlayıcı gücünü kullanarak tek ayak sıçrama ile vücut ağırlığını öne doğru hareket ettirmektedir. Bu hareketler birbirlerine benzerlik gösterdiğinden dolayı aralarında güçlü bir ilişki olduğu söylenebilir. Sporcuların kısa mesafe sprint performanslarının gelişimleri için, antrenman programlarına patlayıcı güç gerektiren (durarak uzun atlama, dikey sıçrama gibi) çalışmaların dahil edilmesi önerilmektedir.

Yayın Etiği: $\mathrm{Bu}$ çalışmanın hazırlanma ve yazım sürecinde "Yükseköğretim Kurumları Bilimsel Araştırma ve Yayın Etiği Yönergesi” kapsamında bilimsel, etik ve alıntı kurallarına uyulmuş olup; toplanan veriler üzerinde herhangi bir tahrifat yapılmamış ve bu çalışma herhangi başka bir akademik yayın ortamına değerlendirme için gönderilmemiştir.

Çıkar Çatışması: Yazarlar, herhangi bir çıkar çatışması olmadığını beyan etmektedir.

Araştırmacıların Katkı Oranı Beyanı: Araştırma Dizaynı- HE; EÇ, Verilerin Toplanması HE, AYÖ, İstatistik Analiz- EÇ; Makalenin hazırlanması, HE, EÇ, AYÖ 
Egesoy, H., Çelik, E. ve Öksüzoğlu- Yapıcı, A. (2021). Genç futbolcularda sürat, güç ve el kavrama kuvvet değerleri arasındaki ilişkinin incelenmesi. Ulusal Spor Bilimleri Dergisi, 5(2), 154-162.

\section{KAYNAKLAR}

Ağılönü, A. ve Kıratlı, G. (2015). 8 Haftalık pliometrik antrenmanın 12-16 yaş kadın hentbolcuların bazı fiziksel uygunluk parametrelerine etkisinin incelenmesi. International Journal of Human Sciences, 12(1), 1216-1228.

Armstrong, C.A. \& Oldham J.A. (1999). A comparison of dominant and non-dominant hand strengths. J Hand Surg, 24(4), 421-425. DOI: 10.1054/jhsb.1999.0236.

Aslan, C.S., Karakollukçu, M. ve Fişne, M. (2015). U-14 Futbol takımı oyuncularının motorik özelliklerinin belirlenmesi. Hacettepe Üniversitesi, Antrenman Bilimi Kongresi, Poster Sunum.

Astrand, P.O. ve Rodahl, K. (1986.) Textbook of work physiology: Physiological bases of exercise. 3rd Edition. Newyork: McGraw-Hill.

Balsalobre-Fernándeza, C. Glaister, M. \& Lockey R.A. (2015). The validity and reliability of an iPhone app for measuring vertical jump performance. Journal of Sports Sciences, 33(15), 1574-1579. DOI: 10.1080/02640414.2014.996184.

Baydil, B. (2006). Eurofit testleri ile 12-14 yaş grubu erkek öğrencilerin fiziksel uygunluk normlarının araştırılması. Ahi Evran Üniversitesi Kırşehir Ĕ̈itim Fakültesi Dergisi (KEFAD) 7(2), 79-87.

Brechue, W.F. Mayhew, J.L. \& Piper, F.C. (2010). Characteristics of sprint performance in college football players. Journal of Strength and Conditioning Research, 24(5), 1169-1178. DOI: 10.1519/JSC.0b013e3181d68107.

Çalış, M. (1992). Beden ĕgitimi dersine katılan katılmayan ve spor yapan 15-16 ya grubu erkek ögrencilerin fizyolojik parametrelerinin eurofit test bataryasıyla mukayesesi. Yayımlanmamış Yüksek Lisans Tezi, Gazi Üniversitesi. Sağlık Bilimleri Enstitüsü, Ankara.

Cardinale, M., Newton, R. \& Kazunori, N. (2011). Speed and agility assessment. in strength and conditioning: Biological principles and practical applications. Wiley-Blackwell: West Sussex, UK, 259-277.

Castagna, C. \& Castellini E. (2013). Vertical jump performance in Italian male and female national team soccer players. J Strength Cond Res., 27(4), 1156-61. DOI: 10.1519/JSC.0b013e3182610999

Cerrah, A.O., Polat, C. \& Ertan, E. (2011). Evaluating some physical and technique chracteristics of super amateur soccer players according to their playing positions. Nigde University Journal of Physical Education and Sport Sciences, 5(1), 1-6.

Eniseler, N. (1995). Futbolda süratin görünümü. Futbol Bilim ve Teknoloji Dergisi, (1), 3-5.

Eyüpoğlu, E. ve Aslan, C.S. (2016). U-15 futbol takımı oyuncularının motorik özelliklerinin belirlenmesi, International Journal of Science Culture and Sport (IntJSCS), 4(3), 864-869. DOI: 10.14486/IntJSCS636.

Girard, O., \& Millet, G.P. (2009). Physical determinants of tennis performance in competitive teenage players. J Strength Cond Res., 23(6), 1867-72. DOI: 10.1519/JSC.0b013e3181b3df89

Gordon, C.C., Churchıll, T., Clauser, C.E., Bradtmıller, B., Mcconville, J.T., Tebbetts, I., Walker, R.A. (1989). 1988 Anthropometric Survey of U. S. Army Personnel: Summery Statistics Interim Report. Technical report: Natick/ TR-89/027, Natick, MA: U.S. Army Natick RD\&E Center.

Günay, M., Tamer, K., Cicioğlu, İ. (2006). Spor fizyolojisi ve performans ölçümü. Ankara: Gazi Kitabevi, 543-545.

İşleğen, Ç., Karamızrak, O., Ertat, A., Varol, R. (1989). 15-17 yaş Genç milli futbol takımlarının bazı sağlık muayene sonuçları, vücut kompozisyonu ve fiziksel uygunluk özellikleri. Spor Hekimliği Dergisi, 24(3-4), 71-77.

Kamar, A., Güngördü, O., Yüceyılmaz, B., Yancı, H.B.A., Çavuşoğlu, B., Şahin, M. (2011). Futbol oyuncularının 35 m maksimal anaerobik sprint ile dikey sıçrama ve durarak uzun atlama skorları arasındaki ilişkinin incelenmesi. İstanbul Üniversitesi Spor Bilimleri Dergisi, (3), 147-150. 
Egesoy, H., Çelik, E. ve Öksüzoğlu- Yapıcı, A. (2021). Genç futbolcularda sürat, güç ve el kavrama kuvvet değerleri arasındaki ilişkinin incelenmesi. Ulusal Spor Bilimleri Dergisi, 5(2), 154-162.

Karavelioğlu, M.B. (2008). Mevkilerine göre amatör futbolcuların fiziksel, fizyolojik ve psikomotor özelliklerinin araştırılması (kütahya ili örneği). Yüksek Lisans Tezi, Dumlupınar Üniversitesi Sosyal Bilimler Enstitüsü Beden Eğitimi ve Spor Anabilim Dalı, Kütahya.

Kramer, T., Huijgen, B.C., Elferink-Gemser, M.T., Visscher, C. (2016). A Longitudinal study of physical fitness in elite junior tennis players. Pediatr Exerc Sci; 28(4), 553-64. DOI:10.1123/pes.2016-0022.

Karabulak, A., Kılınç F. (2016). 12-14 yaş erkek futbolculara uygulanan kombine antrenmanlarının performanslarına etkisinin araştırılması. Journal of Current Researches on Social Sciences, 6(2), 79-96.

Kürkçü, R., Özdağ, S., Afyon, Y.A., Yaman, Ç. (2009). 10-12 yaş grubundaki futbolcu ve badmintoncularda bazı fiziksel ve fizyolojik özelliklerinin karşılaştırılması. Uluslararası İnsan Bilimleri Dergisi, 6(1), 548-556.

Koç, H. (1996). 14-16 yaş grubu hentbolcu ve beden eğitimi dersi alan öğrencilerin bazl fiziksel ve fizyolojik parametrelerinin eurofit test bataryasında değerlendirilmesi. Yüksek Lisans Tezi, Gazi Üniversitesi Sağlık Bilimleri Enstitüsü Beden Eğitimi ve Spor Anabilim Dalı, Ankara.

Köklü, Y., Özkan, A., Alemdaroğlu, U., Ersöz, G. (2009). Genç futbolcuların bazı fiziksel uygunluk ve somatotip özelliklerinin oynadıkları mevkilere göre karşılaştırılması. Spormetre Beden Eğitimi ve Spor Bilimleri Dergisi, 7(2), 61-68. DOI:10.1501/Sporm_0000000151.

Loko, J., Aule, R., Sikkut, T., Ereline, J., Viru, A. (2000). Motor performance status in 10 to 17-year-old estonian girls and boys. Scand J. Med Sci Sports, 10(2), 109-113. DOI: 10.1034/j.1600-0838.2000.010002109.x

Los Arcos, A., Jurdan, M., \& Yanci, J. (2014). Specificity of jumping, acceleration and quick change of direction motor abilities in soccer players. Kinesiology, (49), 22-29. https://doi.org/10.26582/k.49.1.12

O’Donoghue, P.G., Boyd, M., Lawlor, J., Bleakley, E.W. (2001). Time-motion analysis of elite, semi-professional and amateur soccer competition. Journal of Human Movement Studies, (41), 1-12. DOI:10.1080/24748668.2002.11868259

Özkara, A. (2002). Futbolda testler. Ankara: İlksan Matbaacilık.

Polat, Y., Çınar, V., Kesler, A., Adıgüzel, R. (2003). 15 yaş çocuklarının fiziksel uygunluk düzeylerinin incelenmesi, $\dot{I}$. Ü. Dergisi, $11(3)$ (ÖS),109-113.

Pekel, A.H., Balcı, E., Atalay, N.G., Onay, M. (2004) Spor yapan çocukların performansla ilgili fiziksel uygunluk test sonuçları ile antropometrik özellikleri arasındaki ilişkilerin incelenmesi, VIII. Spor Bilimleri Kongresi Özet Kitapçı̆̆g, Antalya, s 110.

Peterson, P., Petrick, M., Connor, H., Conklin, D. (1989). Grip strength and hand dominance: challenging the $10 \%$ rule. Am J Occup Ther, (43), 444-447. https://doi.org/10.5014/ajot.43.7.444.

Reilly, T. (ed.) (1996). Science and Soccer. London: E. \& F.N. Spon.

Saygın, Ö., Gürsoy, R., Tekin, A., Ceylan, H.İ., Babayiğit İrez, G. (2017). 14-15 yaş grekoromen stil güreşçilerin dikey sıçrama, anaerobik güç, el kavrama kuvveti, 30m sprint, aerobik kapasite değerlerinin sikletlere göre karşılaştırılması. ATABESBD, 19(3), 36-50.

Seger, J.Y., Thorstensson, A. (2000). Muscle strength and electromyogram in boys and girls followed through puberty. European Journal of Applied Physiology, 81(1-2), 54-61. DOI: 10.1007/PL00013797.

Seiler, S., Taylor, M., Diana, R., Layes, J., Newton, P. \& Brown, B. (1990). Assessing anaerobic power in collegiate football players. Journal of Applied Sport Science Research, 4(1), 9-15. DOI:10.1519/00124278-19900200000003.

Stolen, T., Chamari, K., Castagna, C., Wisloff, U. (2005). Physiology of soccer: An update. Sports Med., 35(6), $501-536$. DOI: $10.2165 / 00007256-200535060-00004$ 
Taşkın, C., Karakoç, Ö., Acaroglu, E., Budak, C. (2015). Futbolcu çocuklarda seçilmiş motorik özellikler arasındaki ilişkinin incelenmesi. Spor ve Performans Araştırmalarl Dergisi, 6(2), 101-107. https://doi.org/10.17155/spd.74072

Vescovi, J.D., McGuigan, M.R. (2008). Relationships between sprinting, agility, and jump ability in female athletes. $J$ Sports Sci., 26(1), 97-107. DOI:10.1080/02640410701348644.

Wisloff, U., Castagna, C., Helgerud, J., Jones, R. \& Hoff, J. (2004). Strong correlation of maximal squat strength with sprint performance and vertical jump height in elite soccer players. British Journal of Sports Medicine, 38(3), 285- 288. DOI:10.1136/bjsm.2002.002071.

Yelken, M.E., Orhan, Ö. \& Yarım, İ. (2018). Evaluation of the relationship between jump performances and sprint performances of professional football players. 16. International Sport Sciences Congress. pp. 85-90

Yıldız, S., Pınar, S., Gelen, E. (2017). Çocuk tenisçilerde fonksiyonel antrenman: LAP Lambert Academic Publishing.

Yitik, R., \& Ateş, B. (2020). Evaluation of the relationship between sprint and change of direction speed in youth male soccer players using two vertical jumping tests. Future Visions Journal, 4(1), 50-54. DOI:10.29345/futvis.71.

Young, W.B., Mcdowell, M.H., Scarlett, B.J. (2001). Specificity of sprint and agility training methods. Journal of Strength and Conditioning Research, 15(3), 315-319.

Young, W., Farrow, D. (2006). A review of agility: practical applications for strenght and conditioning. Strength \& Conditioning Journal, 28(5), 24-38. DOI:10.1519/00126548-200610000-00004.

Zileli, R. ve Söyler, M. (2021). The examination of the relationship between sprint and vertical jump in soccer players. Manas Sosyal Araştırmalar Dergisi, 10(1), 485-491.

Zorba, E., Saygın, Ö. (2013). Fiziksel aktivite ve fiziksel uygunluk. Ankara: Fırat Matbaacılık.

Bu eser Creative Commons Atıf-Gayri Ticari 4.0 Uluslararası Lisansı ile lisanslanmıştır. 